\title{
O CUIDAR EM ENFERMAGEM: FAMÍLIA E CRIANÇA COM DOR ONCOLÓGICA
}

Grassele Denardini Facin Diefenbach ${ }^{1}$, Maria da Graça Corso da Motta²

RESUMO: Este estudo teve como objetivo conhecer a atuação da equipe de enfermagem no cuidado à criança com dor oncológica em ambiente hospitalar, sob a ótica da família. Trata-se de um estudo exploratório descritivo com abordagem qualitativa, realizado na Unidade de Hematologia e Oncologia Pediátrica de um hospital de grande porte da capital do Rio Grande do Sul, entre maio e junho de 2010. Participaram do estudo 9 famílias; utilizou-se para coleta dos dados o Método Criativo Sensível, através de dinâmicas de criatividade e sensibilidade, analisados conforme referencial da Análise Temática. Constatou-se que a dor resiste a definições, constantemente aterroriza a criança, e essa alcança lenitivo em seu porto seguro - a família. Tais circunstâncias abrem caminhos para a atuação da enfermagem pois, remetem ao aprofundamento dos conhecimentos do saber e fazer em Enfermagem, possibilitando visualizar e interpretar as diferentes realidades da criança com dor oncológica e de sua família.

PALAVRAS-CHAVE: Dor; Oncologia; Criança; Família; Enfermagem.

\section{NURSING CARE: THE FAMILY AND THE CHILD WITH ONCOLOGICAL PAIN}

ABSTRACT: This study aimed to investigate the functioning of the nursing team in the care for children with oncological pain in the hospital environment, from the standpoint of the family. It is an exploratory, descriptive study with a qualitative approach, undertaken in the Pediatric Hematology and Oncology Center of a large hospital in the capital of Rio Grande do Sul, Brazil, between May and June 2010. Nine families participated in the study; the Creative-Sensitive Method was used for the collection of data, through dynamics of creativity and sensitivity, which was analyzed through the framework of Thematic analysis. It was determined that the pain resists definition, constantly terrorizing the child, who is soothed in her 'safe haven' - the family. Such circumstances open avenues for the role of nursing, as they lead to the deepening of knowledge of knowing and doing in Nursing, making it possible to visualize and interpret the different realities of the child with oncological pain and their family.

KEYWORDS: Pain; Oncology; Child; Family; Nursing.

\section{EL CUIDAR EN ENFERMERÍA: FAMILIA Y NIÑO CON DOLOR ONCOLÓGICO}

RESUMEN: Este estudio tuvo el objetivo de conocer la actuación del equipo de Enfermería en el cuidado al niño con dolor oncológico en ambiente hospitalar, bajo el punto de vista de la familia. Es un estudio exploratorio descriptivo con abordaje cualitativo, realizado en la Unidad de Hematología y Oncología Pediátrica de un gran hospital de la capital de Rio Grande do Sul, entre mayo y junio de 2010. Participaron del estudio nueve familias; para recoger los datos fue utilizado el Método Creativo Sensible, a través de dinámicas de creatividad y sensibilidad, analizados de acuerdo con referencial del Análisis temática. Se cloncluyó que el dolor resiste a definiciones, constantemente aterroriza el niño y alcanza lenitivo en la familia. Tales circunstancias posibilitan la actuación de la Enfermería, pues están relacionadas a la profundización de los conocimientos del saber y hacer en Enfermería, ayudando a visualizar e interpretar las diferentes realidades del niño con dolor oncológico así como de su familia.

PALABRAS CLAVES: Dolor; Oncología; Niño; Familia; Enfermería.

*Artigo extraído da dissertação de mestrado intitulada Dor em Oncologia: Percepção da Família da Criança Hospitalizada, apresentado ao Programa de Pós-Graduação em Enfermagem da Universidade Federal do Rio Grande do Sul - PPGENF UFRGS, 2011.

${ }^{1}$ Enfermeira. Mestre em Enfermagem. Professora do Centro Universitário Franciscano - UNIFRA. Membro do Grupo de Estudos no Cuidado à Saúde nas Etapas da Vida - CEVIDA da Universidade Federal do Rio Grande do Sul - UFRGS.

${ }^{2}$ Enfermeira. Doutora em Filosofia em Enfermagem. Professora Associada no Departamento de Enfermagem e Coordenadora do Programa de Pós-Graduação em Enfermagem da UFRGS. Coordenadora CEVIDA 


\section{INTRODUÇÃO}

O processo de cuidar da criança com dor oncológica hospitalizada é componente fundamental do tratamento do câncer em si. O processo de alívio da dor e a atenção dada aos aspectos sociais da doença devem estar inseridos na atenção integral que a criança em processo de adoecimento deve receber. Considerando que a hospitalização, além de sinônimo de total exposição do corpo, representa para a criança uma situação nova, diferente de todas as outras experiências vividas por ela, não se deve, à medida que é internada no hospital, percebê-la como um corpo fragmentado, passível de ser manipulado, codificado e mensurado por diferentes pessoas, em diferentes turnos.

$\mathrm{O}$ ato de cuidar é algumas vezes menosprezado, à medida que pode ser realizado de forma mecanicista, sem a participação do paciente e familiares e com resignação do paciente; transcende a barreira mecanicista, pois essas ações demonstram apenas a forma e o movimento da expressão corporal de um ser único, aquele a quem estamos cuidando. Consequentemente, o cuidado se apresenta como um ideal que deve ser inserido, na sua integralidade, no cotidiano da saúde. Tido como um fenômeno existencial, relacional e contextual, que sofre influências de diversos fatores, é considerado como fenômeno responsável pela humanização. É na Enfermagem que o cuidado se concretiza plenamente e se profissionaliza, ao ocupar o privilégio de estar presente ${ }^{(1)}$.

Durante a internação hospitalar, um dos momentos em que ocorre a ruptura da vida cotidiana da criança, sobrevém a carência de presença, e é dessa forma que a Enfermagem, por vezes, funciona como doadora de presença e de atenção, doadora de tempo, figuras fundamentais para restabelecer os laços entre o paciente e a vida ${ }^{(2)}$. Neste sentido, a Enfermagem pode auxiliar o ser humano na busca da compreensão da dor, do sofrimento, da doença e de sua existência. A criança é um corpo biológico que se está construindo simbolicamente, vulnerável, física e emocionalmente ao processo de doença, devendo ser protegida, auxiliada e cuidada ${ }^{(3)}$.

Outrossim, a criança com câncer, está sujeita, durante o processo de adoecimento, a sentir dores decorrentes da doença e/ou do próprio tratamento; nesse caso, é imprescindível que a família, juntamente com a equipe de enfermagem, possa trabalhar de maneira eficaz, considerando sempre a criança, pois é quem melhor descreve suas necessidades, mesmo que tenha exigências e expectativas fantasiosas.
Segundo o Conselho Nacional dos Direitos da Criança e do Adolescente (Resolução n. 41, de outubro de 1995, item 7), a criança tem o direito de não sentir dor sempre que houver meios para evitá-la ${ }^{(4)}$. Para tanto, faz-se necessário conhecimento e não subtratação da dor por parte dos profissionais da saúde. Aconselha-se, então, sempre acreditar na criança, e assessorar-se da família, por melhor conhecê-la, pelo convívio desde sua mais tenra idade até o momento do diagnóstico da doença, e em todo o período de hospitalização. À Enfermagem cabe, à medida que tem a capacidade de avaliar a dor, minimizar a sensação dolorosa e compartilhar as experiências com a criança e a família, a qual deve ser considerada como o primeiro núcleo provedor de cuidados, com vistas a suprir as necessidades da criança com dor oncológica

Compartilhar a dor da doença com a família é, muitas vezes, sofrer mais do que a própria criança, mas, mesmo assim, manter-se racional e cooperante. Além disso, aos profissionais de saúde, é fundamental conseguir identificar e avaliar as necessidades específicas da criança e a capacidade da família para assumir o papel de prestadora de cuidados. Frente a esse contexto suscitam-se questionamentos sobre o comportamento da equipe de enfermagem no cuidado a criança com dor oncológica em ambiente hospitalar, sob a ótica da família, considerando-a parte integrante do cuidado. Ressalta-se que este estudoé parte da dissertação intitulada: Dor em oncologia: Percepção da família da criança hospitalizada ${ }^{(5)}$ que teve como objetivo geral conhecer a percepção da dor em oncologia, na ótica da família de crianças com diagnóstico de câncer, em ambiente hospitalar.

Considerando que a doença da criança favorece o desequilíbrio e o adoecimento familiar, a Enfermagem pode ir além, visando a um cuidado integral e inserindo a família, a qual igualmente necessita de suporte e apoio, a fim de alcançar independência e administrar os cuidados necessários à situação vivida. A proposta em aprofundar a temática levou em consideração o importante papel da equipe de enfermagem no cuidado da criança com dor oncológica, assim como de sua família, a fim de minimizar seus sofrimentos.

\section{MÉTODO}

Trata-se de uma pesquisa exploratório-descritiva com abordagem qualitativa, que teve como cenário de estudo uma unidade de Hematologia e Oncologia Pediátrica de um hospital de grande porte, localizado na cidade de Porto Alegre, Rio Grande do Sul; o estudo 
foi aprovado pelo do Comitê de Ética em Pesquisa sob o protocolo n. 10.0008 .

$\mathrm{Na}$ instituição, especificamente na Unidade de Hematologia e Oncologia Pediátrica, é possível visualizar e participar das constantes reuniões interdisciplinares, ocorridas semanalmente, evidenciando que o Enfermeiro e outros profissionais atuam juntos com vistas à atenção integral da criança. Constata-se, ainda, que os Enfermeiros estão em constante processo de atualização relativa ao histórico, evolução, diagnóstico e tratamento das crianças que estão hospitalizadas na Unidade; contudo, com sobrecarga no que se refere ao cuidado.

Foram critérios de inclusão ser familiar cuidador de criança em idade escolar ou pré-escolar, acometida pelo câncer e hospitalizada na referida Unidade, e que apresentasse situação emocional para participação nas etapas da pesquisa. Neste estudo, foram considerados os familiares que estavam acompanhando a criança durante a hospitalização, sendo de, no mínimo, um familiar e, no máximo, dois familiares por criança. Dos 17 familiares convidados, 7 sentiram-se impossibilitados de participar, por não desejarem deixar suas crianças sozinhas; acreditavam que, sem sua presença, as crianças não ficariam bem. Dos 10 que participaram, um participou do primeiro ao terceiro momento, necessitando, porém, retirar-se antes mesmo de iniciar a discussão, pois a criança teve hipertermia e pediu que o chamassem. Assim, o estudo foi constituído por 9 familiares acompanhantes, sendo 7 mães, um pai e uma avó.

Para a coleta das informações, utilizou-se o Método Criativo-Sensível (MCS) ${ }^{(6)}$, por meio de Dinâmicas de Criatividade e Sensibilidade (DCS), especificamente, a dinâmica Livre para Criar. Dessa forma, os que se dispuseram a participar, no primeiro momento, foram recebidos em uma sala onde obtiveram esclarecimentos sobre a pesquisa e seus objetivos e fizeram a leitura do Termo de Consentimento Livre Esclarecido (TCLE); estando de acordo, o assinaram e, em seguida, realizaram a sua apresentação individual. No segundo momento, houve explicação sobre como a dinâmica ocorreria, com a apresentação dos materiais a serem utilizados, como revistas, canetas, folhas de papel ofício, cartolina colorida, tesouras, dentre outros. Também, foi estipulado um tempo para que a produção artística fosse elaborada. No terceiro momento, ocorreu a produção artística individual da dinâmica. No quarto momento, cada participante fez a apresentação da sua produção artística; e no quinto momento, aconteceu a análise preliminar dos dados, com discussão e validação coletiva.

A primeira dinâmica teve a duração de 70 minutos e a segunda, 75 minutos, contados a partir do momento em que ocorreu o início da produção artística. Além disso, concomitante à realização das oficinas, foi construído um Diário de Campo para registro das observações durante as dinâmicas, por meio da utilização de um instrumento previamente organizado, a fim de obter e aproveitar, efetivamente, as informações decorrentes do momento da coleta de informações.

Para este estudo, foram formadas duas oficinas, com familiares diferentes, no decorrer dos meses de maio e junho do ano de 2010. O número de dinâmicas foi estabelecido com base no critério de saturação das informações, ou seja, quando as informações compartilhadas com o pesquisador tornaram-se repetitivas, ou seja, as ideias transmitidas pelos participantes foram compartilhadas antes por outros, e a inclusão de mais participantes não resultava em ideias novas ${ }^{(7)}$.

As informações foram analisadas conforme referencial de Análise de Temática proposta por Minayo ${ }^{(8)}$. Foram constituídos quatro temas: Dor oncológica: o olhar da família; Inserção da família no cuidado à criança com dor oncológica no ambiente hospitalar; Dimensões de vulnerabilidade no mundo da família; $\mathrm{O}$ Cuidar em Enfermagem: a família e a criança com dor oncológica. Neste artigo, apresentam-se os resultados da quarta categoria.

\section{RESULTADOS}

\section{O Cuidar em Enfermagem: a família e a criança com dor oncológica}

Tão antiga quanto a humanidade e o câncer, a dor é considerada um agravante no tratamento da criança com câncer, capaz de gerar desespero, angústia, medo na criança e na família frente ao itinerário da doença oncológica. Assim, o controle da dor e o alívio do sofrimento devem ser de responsabilidade e compromisso do profissional da área da saúde, pois mediante a ação de cuidar, o ser humano humaniza-se, e a Enfermagem está à frente desse Cuidado, uma vez que todo o ser humano é um ser passível de cuidado, valioso em si mesmo.

É o profissional Enfermeiro quem constantemente vivencia as diversas experiências da criança e da família em ambiente hospitalar, de um simples procedimento, ao mais complexo cuidar, como expressa a fala a seguir: 
A primeira atitude minha é de chamar as enfermeiras para dar um medicamento pra acalmar a dor. (Mãe 2)

Observa-se, no discurso do familiar, a confiança que depositam no enfermeiro, já que, no momento de dor da criança, têm como primeira atitude chamá-lo. Nessas ocasiões, esse profissional dispõe de todas as suas habilidades, crenças e experiências no processo do encontro de cuidado, propiciando o diálogo, o que, conforta a família aflita, em momentos dolorosos da criança.

Ser Enfermeiro é fazer-se útil, insubstituível, é ser e estar presente, aberto ao encontro, tornando diálogo viável, como forma de fortalecer o estar bem ou o estar melhor, a fim de contribuir para melhora da criança com dor. Fazer de cada encontro um momento ímpar; assim, ressalta-se a importância do campo perceptivo do Enfermeiro, no que refere-se ao chamado pela família e/ou pela criança, bem como a natureza do diálogo

Quando ele está com dor, falo com os médicos, enfermeiras. (Avó 1)

Observa-se, nesse discurso da Avó 1, que ela encontra alento nos enfermeiros, nas equipes de saúde, confiança, segurança e cuidado. O medo da doença, os momentos de dor constantes vivenciados pela criança, em alguns casos, avultam a importância de um diálogo constante e atento com a família, envidando esforços para que ele transcorra naturalmente. Dessa forma, é de suma importância o inter-relacionamento equipe-familiares, pois, ao "cuidar-se" da família, oferta-se suporte para o enfrentamento de outras situações.

Durante o tratamento, em diversos momentos a criança experiencia a dor. Para tanto, faz-se presente a Enfermagem, apta no auxílio e compreensão da criança e da família, favorecendo o entendimento de sua doença, necessidades de procedimentos, medicações e fomentando a força da família frente, aos seus medos, angústias, inseguranças:

A minha filha diz assim: "Ai mãe, chega de pique, já tô toda picada!!!" Daí, o que tu vai fazer? Vai tirar o braço da tua filha dali e vai sair correndo do hospital? Não! Tem que chegar e conversar [...] eu tento explicar [...] não sei de que forma o certo tu tira palavras de onde tu não tem mais [...] porque, às vezes, a gente também fica assim sem ter palavras pra dizer, mesmo assim a gente tira forças [...] não sei de onde [...] as enfermeira ajuda [...]. (Mãe 1).
A relação entre Enfermeiro e criança é que constitui o processo de cuidar, integrando técnica, intuição, comunicação, diálogo, sensibilidade. A comunicação entre ambos transcende a comunicação verbal. A atuação desse profissional baseia-se no relacionamento interpessoal, com ênfase no trinômio criança/família/ equipe, no ato de cuidar com humanidade, ou seja, ofertar o cuidado merecido por um ser humano, independentemente do seu estado. O cuidar está intrinsecamente relacionado ao colocar-se no lugar do outro.

Mãe, porque a Senhora tá chorando? E eu disse: - Eu não tô chorando [...]. É, mas eu tô sentindo que a senhora tá muito nervosa [...]. Claro, né!!! A gente vê uma coisa, o médico fala uma coisa [...] vem outro, fala outra coisa mais horrivel ainda [...] a gente fica pensando... ai, será que meu filho vai passar por isso?! Será que [...] o que vai acontecer?! A gente não sabe! (Mãe 7)

É nesse contexto que a Enfermagem está presente e considera o ser exclusivo da criança como também sua luta para tornar-se pessoa. Mas, para exigir tanta sensibilidade do Enfermeiro, é preciso evocar suas experiências e percepções, pois, a qualquer momento, pode ocorrer um chamado, tanto da criança como da família, o que, de certa forma, implica em resposta por parte do profissional.

\section{DISCUSSÃO}

A demanda de crianças portadoras de neoplasias nos hospitais é expressiva e tende ao crescimento. Para além dos avanços na área de oncopediatria, a equipe de saúde ainda se depara com situações desafiantes durante o processo de enfrentamento da doença. Dentre estes desafios, salienta-se a dor no câncer infantil, que necessita de diagnóstico e intervenção adequados ${ }^{(9)}$.

De acordo com algumas famílias, os sintomas que causam maiores problemas para as crianças em tratamento do câncer são: estresse emocional, fadiga, nutrição e a dor, sendo esta última a mais problemática. Para tanto são necessários estudos com essa temática, a fim de que os resultados possam nortear as orientações dos profissionais da saúde dentro da oncologia pediátrica ${ }^{(10)}$.

Sendo a dor uma sensação desagradável, é ainda mais angustiante para o familiar experienciar a dor da criança, sem poder fazê-la cessar. É nesses momentos que a Enfermagem tem papel preponderante no que se refere à minimização da dor, conforto da família 
e compreensão da angústia com que a família vê a criança vivenciar essa nova situação. A Enfermagem tem essa capacidade, por estar perto da criança e da família em todos os seus momentos de sofrimento e dor, a postos ao perceber o chamado, disposta ao encontro e aberta ao diálogo, como forma de auxiliar a família no enfrentamento e superação da dor.

Assim, a Enfermagem é a profissionalização da capacidade humana de cuidar, através da aquisição e aplicação de conhecimentos, de atitudes e habilidades apropriadas aos papéis prescritos a ela ${ }^{(1)}$. Contudo, é frequente, na Enfermagem, os profissionais depararem-se com situações que requerem ações e decisões transcendentes aos conhecimentos científicos. Por vezes, a práxis fundamenta-se na sua própria experiência e compreensão de mundo, no qual a doença, a dor, o sofrimento, conferem uma situação de vulnerabilidade à criança com câncer e à família, viabilizando a condição de cuidado.

Percebe-se, então, que a ação de cuidar, de acompanhar, constitui a essência da Enfermagem, a qual se propõe a compreender como se relacionam entre si a saúde, a enfermidade e a conduta humana. Por meio de sua filosofia e ciência dos cuidados, intenta definir as atividades relativas aos aspectos humanísticos da vida ${ }^{(11)}$.

A Enfermagem singulariza-se, a partir do ato de cuidar em relação às outras áreas e ciências da saúde. Cuidar de seres humanos, que sofrem, padecem, ou tratar de ajudar a quem os acompanha é a motivação fundamental da Enfermagem. $\mathrm{O}$ ato de cuidar e acompanhar são processos que incluem a tecnologia com base antropológica, ética e estética, além do intuitivo ${ }^{(11)}$.

Dessa forma, cuidado é o fenômeno resultante do processo de cuidar, o qual representa a forma como ocorre o encontro ou a situação de cuidar entre cuidadora e ser cuidado. Compreende os comportamentos e atitudes demonstrados nas ações pertinentes ao Enfermeiro, asseguradas por lei e desenvolvidas com competência no sentido de favorecer as potencialidades das pessoas para manter ou melhorar a condição humana ${ }^{(1)}$.

Por outro lado, a família também necessita de cuidados e pode, com o seu comportamento, estar expressando e solicitando alento. O conhecimento da criança sobre sua situação é uma variável importante. Ao identificar que a criança não está informada suficientemente, o Enfermeiro pode sanar essa falha, contribuindo para que ela se sinta segura e colabore no processo de cuidado. $\mathrm{O}$ mesmo ocorre com a família: sua presença junto da criança e seu carinho são fundamentais, e a equipe atenta, esclarece, informa, dá apoio, contribuindo para o crescimento do ser cuidado ${ }^{(1)}$.

Por tanto, a ação de cuidar não é algo pontual, e sim contínuo, que se desenvolve paralelamente às etapas do enfermo. A fidelidade e a continuidade são chave no cuidar. Somente é possível cuidar adequadamente se tiver integrado em sua disciplina a pedagogia da vulnerabilidade, o que significa reconhecer a fragilidade do outro. Somente quem é consciente da vulnerabilidade de seu próximo pode cuidá-lo ${ }^{(11)}$.

$\mathrm{E}$, durante o encontro, o simples ato de escutar as angústias, incertezas e medos da família da criança com dor, bem como de dialogar com uma linguagem clara, compreensível, partilhar informações, faz com que o ser cuidador melhore o estado emocional da família e, por conseguinte, da criança. $\mathrm{O}$ ato de cuidar exige da Enfermagem, presença, estar instrumentalizado, pronto para dar e receber atenção, carinho e afeto. Assim, interage-se com a família, facilitando o estar-bem e o estar-melhor, além fortalecer o trinômio criança/família/equipe.

\section{CONSIDERAÇÕES FINAIS}

Apesar do grande avanço científico e tecnológico, o câncer, atualmente, é uma doença com grande incidência de cura, mas ainda de difícil diagnóstico, pois está relacionada a recursos, muitas vezes indisponíveis quando realizados em pequenos centros. Para tanto, tão importante quanto o tratamento do câncer em si e o processo de alívio da dor, é a atenção dada aos aspectos sociais da doença, uma vez que a criança doente deve receber atenção integral, bem como a família.

Nesse contexto, a Enfermagem é o primeiro contato da família no universo hospitalar, um mundo desconhecido e temido para ela. A doença traz à tona novamente situações de vulnerabilidade, conferindo à criança e à família todo o sofrimento, dor, medo, angústia, desgaste físico e mental causados pelo câncer.

Assim, abrem-se caminhos para o saber e fazer da Enfermagem, à medida que atua de forma ímpar, escutando e conhecendo as percepções da família frente à criança com dor oncológica, hospitalizada. Para tanto, é preciso pensar nas peculiaridades rumo à construção dessa relação de cuidar, reconhecendo as singularidades, subjetividades e intersubjetividades, inerentes ao processo de cuidado.

Diante do exposto, é possível refletir a partir da percepção dessas famílias, sobre suas vivências em relação à dor da criança com câncer; buscar subsídios para a reconstrução e/ou construção de ações de 
cuidado, a fim de minimizar o sofrimento de ambas. Levantar ideias e criar expectativas de um cuidar para além da tecnologia. Estar atento à dor, à verbalização da criança e ao sofrimento da família, converge para o sucesso do ser e fazer em Enfermagem.

Considerar a família como indispensável para o cuidado à criança com dor oncológica permite manifestação de seu apoio, amor, carinho, afeto e conforto que representam formas de cuidar, capaz de amenizar o sofrimento do doente com dor. Famílias devem estar presentes no cotidiano mundo do hospital porque necessitam de atenção, bem como ter espaços de discussão, visto que sua presença oferece conforto, segurança e tranqüilidade à criança hospitalizada.

Diante do exposto, acredita-se que reconhecer a singularidade da família frente à criança com dor, é de extrema relevância, a fim de compreender suas peculiaridades, aceitando suas restrições e possibilidades no ato de cuidar. Ao dar voz às famílias das crianças com dor oncológica hospitalizadas, essas expressaram seus sentimentos, medos, angústias, emoções, além de suas compreensões e percepções da dor em oncologia. Oferecendo, desta forma, aos profissionais da saúde subsídios significativos para o aprimoramento de sua prática.

O cuidado à saúde é complexo, não possui padrões absolutos e depende do agir de cada ser humano. Entretanto, ao absorver os saberes, o fazer, a ética, além da subjetividade, prática da enfermagem torna-se imprescindível ao ato de cuidar da criança com dor oncológica e sua família. Recomenda-se, também, que este tema seja ampliado por outras investigações.

\section{REFERÊNCIAS}

1. Waldow VR. Cuidar: expressão humanizadora da enfermagem. $2^{\mathrm{a}}$ ed. Petrópolis: Vozes; 2007.

2. Sant'Anna DB. Corpos de passagem: ensaios sobre a subjetividade contemporânea. São Paulo: Estação Liberdade; 2001.

3. Motta MGC. O ser doente no tríplice mundo da criança, família, e hospital: uma descrição fenomenológica das mudanças existenciais [tese]. Florianópolis (SC): Universidade Federal de Santa Catarina; 1997.

4. Brasil. Lei 8069, de 13 de julho de 1990. Dispõe sobre o Estatuto da Criança e do Adolescente e dá outras providências.Resolução $\mathrm{n}^{\circ}$. 41, de outubro de 1995 , item 7. Diário Oficial da União. [acesso em 12 jan 2009]. Disponível: http://www.planalto.gov.br/ccivil_03/LEIS/ L8069.htm.
5. Diefenbach. GDF. Dor em oncologia: Percepção da família da criança hospitalizada. [Dissertação]. Porto Alegre (RS): Universidade Federal do Rio Grande do Sul; 2011.

6. Cabral IE. O método criativo-sensível: alternativa de pesquisa na enfermagem. In: Gauthier JH, organizador. Pesquisa em enfermagem: novas metodologias. Rio de Janeiro: Guanabara Koogan; 1998. p. 177-203.

7. Polit D, Beck CT, Hungler B. Fundamentos de pesquisa em enfermagem: métodos, avaliação e utilização. $5^{\mathrm{a}}$ ed. Porto Alegre: Artmed; 2004.

8. Minayo MCS. O desafio do conhecimento: pesquisa qualitativa em saúde. 11ª ed. São Paulo: Hucitec; 2008.

9. Bueno PC, Neves ET, Rigon AG. O manejo da dor em crianças com câncer: Contribuições para a enfermagem. Cogitare enferm. [Internet] 2001;16(2). [acesso em 24 ago 2011]. Disponível: http://ojs.c3sl.ufpr.br/ojs2/index. php/cogitare/article/view/20307/14208.

10. Poder U; Ljungman G; von Essen L. Parents' perceptions of their children's câncer-related symptoms during treatment: a prospective, longitudinal study. J. pain symptom manage. 2010;40(5):661-70. DOI: http:// dx.doi.org/10.1016/j.jpainsymman.2010.02.012

11. Torralba RF. Antropologia do cuidar. Petrópolis: Vozes; 2009. 